\title{
Promoting Teachers' Learning and Knowledge Building in a Socio-Technical System
}
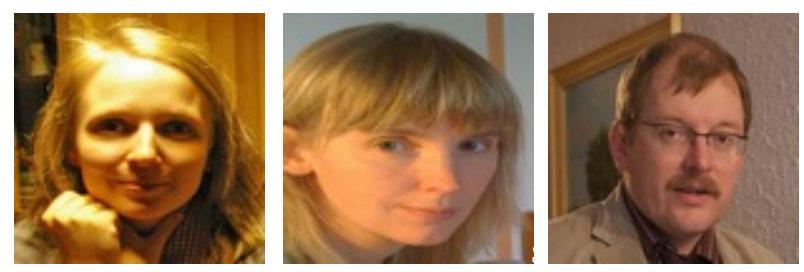

Kairit Tammets, Kai Pata, and Mart Laanpere

Tallinn University, Estonia

\section{Abstract}

The study proposes a way in which the learning and knowledge building (LKB) framework, which is consistent with the knowledge conversion phases proposed by Nonaka and Takeuchi, supports teachers' informal and self-directed workplace learning. An LKB framework in a socio-technical system was developed to support professional development in an extended professional community. The LKB framework was implemented and formatively evaluated in the in-service course that prepares teachers for accreditation in an e-portfolio community. The extended community consisted of 16 participants, in-service teachers and domain experts. The evaluation considered (a) how the LKB practices of the framework became actualized among the community members and (b) what supported these LKB practices. Data were collected from log-files of the portfolio system. Correlation analysis and Bayesian dependency modelling revealed the way in which the bottom-up peer scaffolding from community members influences teachers' LKB practices. As a result, the study proposes that a socio-technical system might promote LKB in a professional community.

Keywords: Socio-technical system; portfolio; teacher development; learning and knowledge building; scaffolding 


\section{Introduction}

This study describes and validates technologically supported learning and knowledge building (LKB) practices in an extended professional community. It substantiates the use of LKB practices as a vehicle for enhancing teachers' on-going professional development. The technology-supported LKB practices in the extended community are conceptualized as an example of the socio-technological system. The authors also propose forms of scaffolding that might promote LKB in such systems.

Currently, teachers' professional development is mainly provided in formal workshops, training courses, and conferences, but in order to benefit from learning experiences insitu, professional development should be an on-going process in the workplace (Duncan-Howell, 2007). Professional development should focus on self-directed learning in the authentic settings that occur while planning, reflecting, and sharing personal learning experiences (Mushayikwa \& Lubben, 2009); learning together with one's peers (Boyle, White, \& Boyle, 2004); and participating at collaborative knowledgebuilding events (Scardamalia \& Bereiter, 2003). A study by Marrero, Woodruff, Schuster, and Riccio (2010) indicated that teachers who participated in online courses and learnt together with peers found this form of learning more supportive than traditional professional development workshops. Online professional development may provide opportunities for integrating teachers' experiences as learners and teachers, claim Mackey and Evans (2011).

In this article the authors support the consideration that learning appears if there has been some significant change in an organization's 'groups', or a person's way of thinking, perceiving, or doing something (Harri-Augstein \& Thomas, 1991). Learning is an internal and hardly observable change in teachers' beliefs through self-analysis, reflection, and competence development that does not necessarily have to be visible to others (Scardamalia, Bereiter, \& Lamon, 1994). Knowledge building (KB), on the other hand is an external, individual, and socially shared knowledge construction process, which results in the formation of various forms of new cognitive artefacts that contain individual, group, and organizational knowledge (Scardamalia \& Bereiter, 2003). The learning and knowledge building practices should be considered together in a professional learning context because they strengthen each other. In order to detect the learning of individuals and organizations, the change process itself - knowledge building, its results and cognitive artefacts - needs to be external and shareable. In selfdirected LKB practices, individuals create the knowledge but are also influenced by, and can learn from, shared organizational and individual knowledge.

Many authors (Boyle, While, \& Boyle, 2004; Huberman, 2001) believe that teachers' learning should be a social process. Hargreaves (1993) said that in order to avoid individualism and isolation in the teaching profession, professional learning should be conducted collaboratively. The current study focuses on an extended professional community established within the context of a school-university partnership for promoting teachers' accreditation. The community of practice concept defines 
communities as groups of people who share a concern or a passion for something they do and who learn how to do it better as they interact regularly (Wenger, 1989). Learning in the community of practice takes place by gradual enculturation to the shared repertoire and understandings. The professional learning community is commonly believed to involve a group of teachers sharing and critically interrogating their practice in on-going, reflective, collaborative, inclusive, learning-oriented, growth-promoting ways (Stoll \&Louis, 2007).

According to Hunter (2002), technology provides teachers with opportunities to collaborate with other teachers and experts outside of their schools. Duncan-Howell (2007) claims that technology supports the development of online communities of teachers, and if in the past the school was the community, then larger communities are formed now. She notes that members of online communities may come from different schools, resulting in a richer community and exposure to a variety of perspectives. Such online communities may support collaboration between the school and university as well, as proposed by Goodland (1994). Such partnerships promote the development of collaborative relationships and improvement of teaching skills and strategies and provide opportunities to update and improve pre-service teacher education programs.

The phenomenon in which human/computer interaction and human communication are systematically integrated is conceptualized as a socio-technical system (Herrmann, 2009). According to Weinberger, Fisher, and Mandl (2002), socio-technical systems bring people together to share information and to collaborate in an environment where scaffolding enhances collaboration and the sharing of individual and group knowledge. Herrmann (2009) also proposed that socio-technical systems could employ social software solutions for supporting learners to become members of communities, to conceptualize the understanding of their learning process, and to receive feedback.

In the current study, the technology support for teachers' LKB in the extended professional community is provided by the socio-technical system comprising social media and the professional community of teachers and educational specialists. There is a need to better understand how the technology-supported extended professional community, as a socio-technical system, promotes teachers' LKB. The role of scaffolding has been claimed to be important for facilitating self-regulated learning in technological environments (Pea, 2004). However, little is known about what kind of scaffolding appears in extended professional communities, and how it may facilitate LKB practices. The aim of this study is to explain how a socio-technical system promotes LKB practices in an extended professional community. The following research questions were formulated:

a) Which LKB practices do the community members perform and could the LKB practices of the framework become actualized among the community members?

b) How does a socio-technical system scaffold LKB practices in the extended professional community? 


\section{The Framework for Organizing Teachers' Learning and Knowledge Building Practices}

For the systemic organization of teachers' LKB practices in the extended professional community, the elaborated knowledge conversion model, developed by Nonaka and Takeuchi (1995), is proposed in this study. The original model focuses primarily on knowledge creation and the transfer of knowledge between implicit and explicit forms and across individual and organizational levels, which makes the model relevant for this study. Knowledge conversion across individual and system levels could be used in the communities similarly as in organizations, assuming that both represent system level phenomena. Nonaka and Takeuchi (1995) describe four knowledge conversion stages (SECI): Socialization (S) between individuals using tacit knowledge then externalizing (E) it in individual reflections in an organizational context that builds the knowledge base for collaborative knowledge; combination (C)facilitates bringing tacit individual knowledge into explicit organizational knowledge and making it reusable for individual learning in internalization (I).

Self-directed and informal learning, as a form of professional development, is not well recognized or understood in the workplace (Lom \& Sullenger, 2010). In the research and practice of knowledge creation, the individual as the carrier of the knowledge has been marginalized (Haag, 2010); although from the self-directed learning perspective, it is the individual's self-motivation that promotes knowledge building and learning. In the context of a teacher's continuous learning, the focus on self-directed learning (SDL) is important (Mushayikwa \& Lubben, 2009) since professional development should arise from a teacher's own initiative (Van Eekelen, Vermunt, \& Boshuizen, 2006). Nonaka and Takeuchi (1995) have not considered self-directed learning as a motivator of organizational learning at the individual level, but the authors argue that selfregulated planning, reflection, and activities that develop competence should be integrated into the externalization and internalization phases of the knowledge conversion model (Pata \& Laanpere, 2008; Tammets, Pata, \& Laanpere, 2011). 


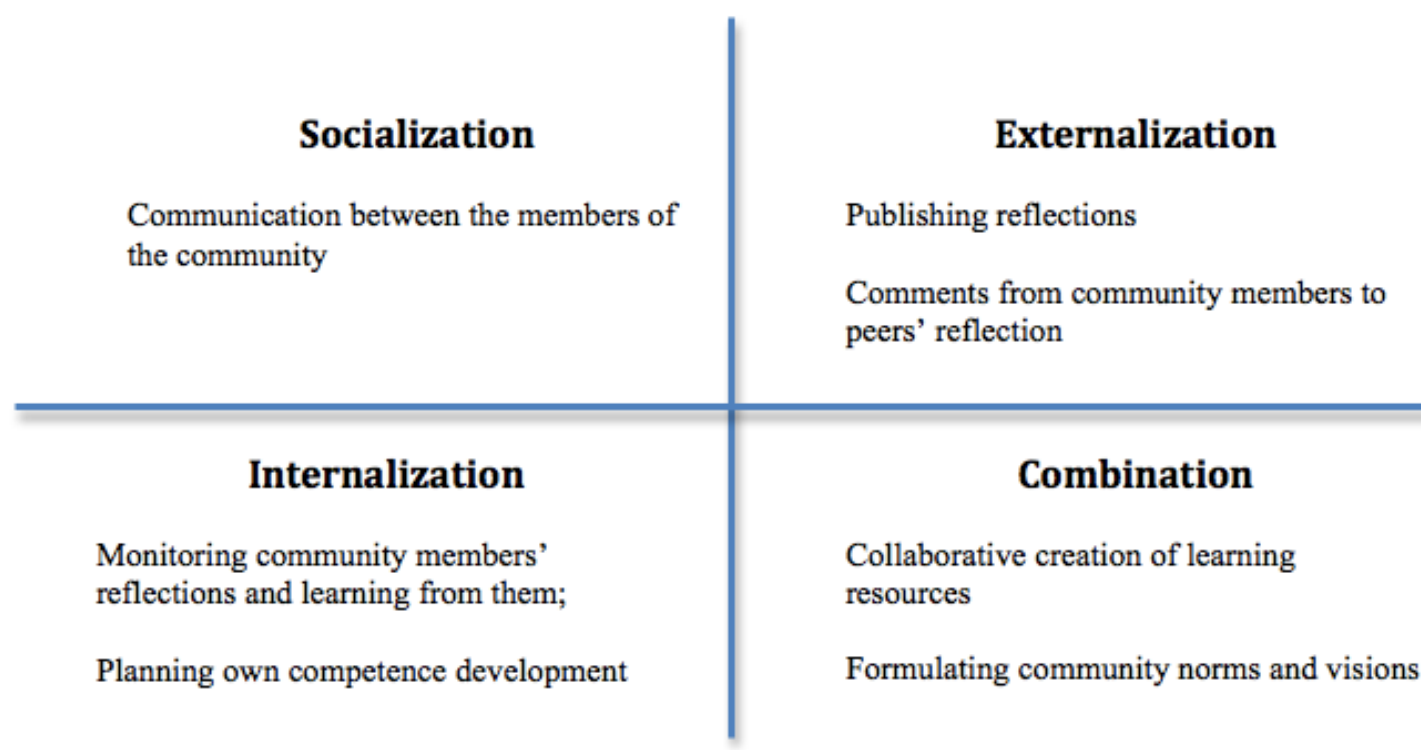

Figure 1. LKB practices in different SECI phases.

The authors propose that using the SECI phases for organizing teachers' LKB practices in an accreditation context enables the creation of a knowledge conversion process in the extended professional community of teachers and educators in which accreditation becomes part of lifelong learning (Tammets, Pata, \& Laanpere, 2012). The exact descriptions of the LKB practices for supporting teachers' development in an extended professional community are discussed in the Results section, but Figure 1 illustrates the general LKB practices in different SECI phases.

\section{Technology-Support for LKB in Teacher Professional Development}

In the current study for organizing LKB practices in a teachers' professional community, the authors used a portfolio-based system that consists of e-portfolios that are shared in an online community. Several studies have highlighted the importance of the e-portfolio in teachers' professional development, because a portfolio can demonstrate compelling evidence of growth and competency (Abrami \& Barrett, 2005). It may also serve as a medium for translating theory into practice (Hauge, 2006). In the e-portfolio, teachers may collect their learning materials, reflections, competence development, and other mainly profession-related content that can illustrate their professional journey over time. Acosta and Liu (2006) argue that an e-portfolio community may promote new and authentic collaboration and enable teachers to reflect and share their experiences; to become inspired by their peers' reflections; to support each other and work together with shared reflections (Acosta \& Liu, 2006). We proposed that in the professional community, the e-portfolio community creates additional possibilities for organizing LKB practices. It can be a free platform not managed by any of the organizations. It 
creates a space and adds structure to the extended professional community. In such a system, a community may have its own community knowledge that is stored and becomes accessible and reusable from the portfolio community (Tammets \& Pata, 2012). A portfolio-based community as a socio-technical system promotes LKB by enabling the community members to (a) write external reflections on actions and share them within the community; (b) find and reuse those external reflections by learning from them, and for creating generalized community knowledge; (c) have collaboration and knowledge building about knowledge, competences, or actions with the community members; and (d) plan professional development based on shared social and community norms.

The role of scaffolds in facilitating self-regulated learning has been found to be a critical issue in online learning environments (Pea, 2004). Pea sees two threads in the scaffolding concept coming together, a social process and a tool/technology process, but the scaffolds are not found in the software; rather, they are functions of processes that relate people to the performances in systems over time. Inspired from these two dimensions of a scaffold, this study emphasizes two types of scaffolding: peer scaffolding and socio-technical scaffolding.

\section{Peer scaffolding.}

Several studies have emphasized that scaffolding is a social process. The term "scaffolding" was introduced by Wood, Bruner, and Ross (1976), who described scaffolding as a process that enables a child or novice to solve a problem, carry out a task, or achieve a goal which would be beyond his unassisted effort. In this study, the concept of a peer is seen in the context of an extended professional community where the peers can be the members of different communities in relation to a teacher's professional development. In this study the teachers from different schools and domain experts from different universities and teacher organizations are seen as peers in the professional community who could provide peer scaffolding to individuals from the professional community. In the current study, the authors differentiate between peers in an extended professional community: (a) a peer from a university (domain expert), (b) a peer from a teachers' organization (domain expert), and (c) a peer from a school (teacher). Pata, Lehtinen, and Sarapuu (2006) proposed the multi-actor scaffolding model - one in which the inter-relationships between verbal tutors and peer scaffolding, during a collaborative process, were outlined. According to this model, tutor and students frequently elaborate and replace each other's scaffolding acts in a collaborative situation. It was found that a tutor's dominating type of scaffolding encourages students to take a more passive role by interacting mainly with their tutor and to a lesser degree with their peers. However, if tutor and students elaborated each other's scaffolding acts, this might facilitate the students' productive discourse more than the tutor's scaffolding alone. In the current study, the role of different types of peer scaffolding on a teacher's LKB practices was of interest. 


\section{Socio-technical scaffolding.}

Puntambekar and Hubscher (2005) have said that owing to advancements in technology, scaffolding is no longer restricted to interactions between a human expert and a learner. Such interactions have been extended to include the use of technological tools, resources, environments, and so on. An example of socio-technological scaffolding is the Knowledge Forum, developed to scaffold the knowledge-building framework (Scardamalia \& Bereiter, 1994). This system guides educators in providing scaffolding for sharing ideas and thoughts within a networked database, making knowledge artefacts available for others to work on and to be elaborated further. In the Knowledge Forum, the weblog, forum, and the personal portfolio mediate the accumulated knowledge of the community, providing scaffolding for the community members.

\section{Methodology}

\section{Research Design and Case Description}

This study follows the case study methodology for data collection. Yin (1984) defined the case study as an empirical inquiry that investigates a contemporary phenomenon within its real-life context, when the boundaries between phenomenon and context are not clearly evident and in which multiple sources of evidence are used. The case study method includes the following steps: (a) determine and define the research questions; (b) select the cases and determine data gathering and analysis techniques; (c) prepare to collect the data; (d) collect data in the field; (e) evaluate and analyse the data; (f) prepare the report. The same steps were followed in this study. Using the case study approach in this study demonstrates the current trends of research in education. As Creswell (2005) claims, case studies focus on real activities; therefore the case study approach was chosen for this research in order to get an insight into teachers' actual LKB practices in a technology-supported extended professional community.

The study was conducted in collaboration with the EU funded 7th FP project IntelLEO, whose aim is to explore supportive technologies for LKB practices of learners in extended organizations. In collaboration with the project, the study was designed to support teachers' LKB practices using a portfolio-based learning environment during an in-service training course. Partially web-based, the course supported the activities in the extended professional community. The community members could socialize and reflect on actions, initiate or participate in collaborative practices, learn from the reflections of others as well as from the community knowledge, and scaffold their colleagues. However, the formation of real professional communities takes a much longer time period than a three-month training course and admittedly this imposes a limitation on this study. 
The environment for the professional community was designed on the open-source Elgg platform that is a portfolio-based community. Elgg supports individual development of the users with portfolio functionalities, such as writing entries in a personal weblog, uploading files, and development of materials with the collaboration tool. From the community-building aspect, Elgg supports creating communities, socializing in a forum, and co-developing materials with peers. The Elgg platform was used since Estonian teachers can use the analogical e-portfolio community "Koolielu” (http:// koolielu.ee) for their professional community activities and for personal development. However, the authors chose not to use Koolielu directly because it does not enable automatic datacollection of user-activities at the level required in this study.

For encouraging the development of the extended professional community, the following course modules were designed.

(a) Topic: Accreditation and e-portfolio. Theoretical material concerning an e-portfolio in the accreditation context was required reading (internalization). Discussions about theoretical material (combination) were to be performed in the forum. Additionally participants were required to start preparing their accreditation e-portfolios (externalization). When needed, participants were required to use the forum to socialize by asking questions and expressing their uncertainties (socialization). This module supported the idea that a member of the extended professional community could prepare the professional development portfolio for authentic lifelong learning and use it in the accreditation or other types of certification/ evaluation processes.

(b) Topic: Competence-based education. Theoretical material concerning competencebased professional development was required reading (internalization). Discussions about material (combination) were to be performed in the forum. Additionally participants were required to reflect on how they acquired one educational technology competence that was pre-defined by the domain experts. The guidelines for reflection were available to the community. Subsequently, participants were required to divide themselves into groups and collaboratively combine their individual reflections in 'shared knowledge'. As a result of this collaborative task, community members then formulated the kind of activities that could be performed for acquiring a certain competence and identified which resources might be supportive in this competence development process. This module illustrated that if individuals analyse and plan their own development in accordance with the competency standard and include evidence in the form of illustrative materials, the planning and analysis process is systematic.

(c) Topic: SECI model as a theoretical baseline for teacher education. The last module (b) was similar to the previous one (a) - reading and discussing the theoretical material was presented and individual reflections and collaborative tasks were performed. That module shaped and nurtured the idea of reflection in the community and a focus on theory-driven (SECI) teacher development. 
All the activities in the modules are associated with some SECI phases and enable knowledge creation at the individual and community level.

\section{Data Collection and Analysis}

The data were collected from 16 participants in the study. Of these, 13 were experienced Estonian secondary school teachers who intended to prepare themselves in order to pass the accreditation process for reaching the next level in their career path and three were domain experts from the university and from the teacher's professional union. These participants constituted the members of this extended professional community. For analysing teachers' LKB practices and determining the scaffolding logging traces in the system was used for collecting the data.

\section{Logging users' activities in the online system.}

To validate if and how the planned LKB practices took place between the community members and to find an answer to research question 1, the study used log data for analysing the interactions in the system. A special activity-logging tool was developed as an add-in module for the Elgg-based portfolio system. The log contained all the data relating to the actions that the users performed in the system in an extended Activity Streams format. Each log record contained the username, action, object, time-stamp, and context (e.g., "username1 added blog post at 27th December 201117.06 p.m. to the community X page").

In the next phase, one researcher categorized all of the actions in the log-file, mainly based on the SECI phases. Teachers' (T) and domain experts' (O) socialization activities were categorized as S_T and S_O. Externalization activities were divided into writing a blog entry $\mathrm{E}$ (Entry)T or commenting on a blog $\mathrm{E}$ (Comment)T or $\mathrm{E}$ (Comment)O. Combination activities in the forum were categorized as $\mathrm{C}_{-} \mathrm{T}$ and $\mathrm{C}_{-} \mathrm{O}$. In addition, the activity view was categorized as View $\mathrm{T}$ and View $\mathrm{O}$ and this included viewing the weblogs, forums, and materials. This type of approach supports analysing the peer scaffolding. Every comment and discussion thread was manually checked to see if the teacher's purpose was to collaborate or socialize in the forum. Internalization in this study was not measured. Log-information from the system indicated that teachers often just looked at the posts in the discussion forum, peers' blogs, or theoretical learning materials. In this study "the viewing within the system" is considered as an action of "viewing". The data was categorized and discussed with another researcher and in cases where the researchers had differing opinions the data was not categorized until both researchers reached agreement in their decision. The study did not analyse internalization and learning using the log data. It can also be assumed that cognitively one interaction in the system may involve more than one SECI activity. For example, while commenting on a peer's blog (E-phase), a teacher may also learn at the same time (I-phase).

A total of 1,789 occurrences of LKB practices were identified within 15 weeks. The interactions were counted and organized into the weekly frequency data matrix. Firstly, 
the correlation analysis with SPSS 18.0 software was performed to identify associations between the interactions. Secondly, the web-based Bayesian dependency-modelling tool B-course (Myllymäki, Silander, Tirri et al., 2002) was used to model the dependencies and make assumptions about how the LKB interactions influenced each other as a system. The naïve causal dependency model was drawn, leaving aside (for the sake of simplification) the possibility that the dependencies could be caused by unmeasured variables. During the search 2,749,453 candidate models were evaluated, but the last 2,392,158 evaluations did not result in finding better models.

\section{Results}

\section{LKB Practices in the Extended Professional Community}

In order to establish the professional community, the practices from our LKB framework (Tammets et al., 2011, 2012) were adapted to the teacher accreditation context and embedded into the socio-technical system (Figure 2). The aim was to develop the systemic LKB practices that would support the creation of the community knowledge based on the sharing and accumulation of individual professional knowledge and experiences.

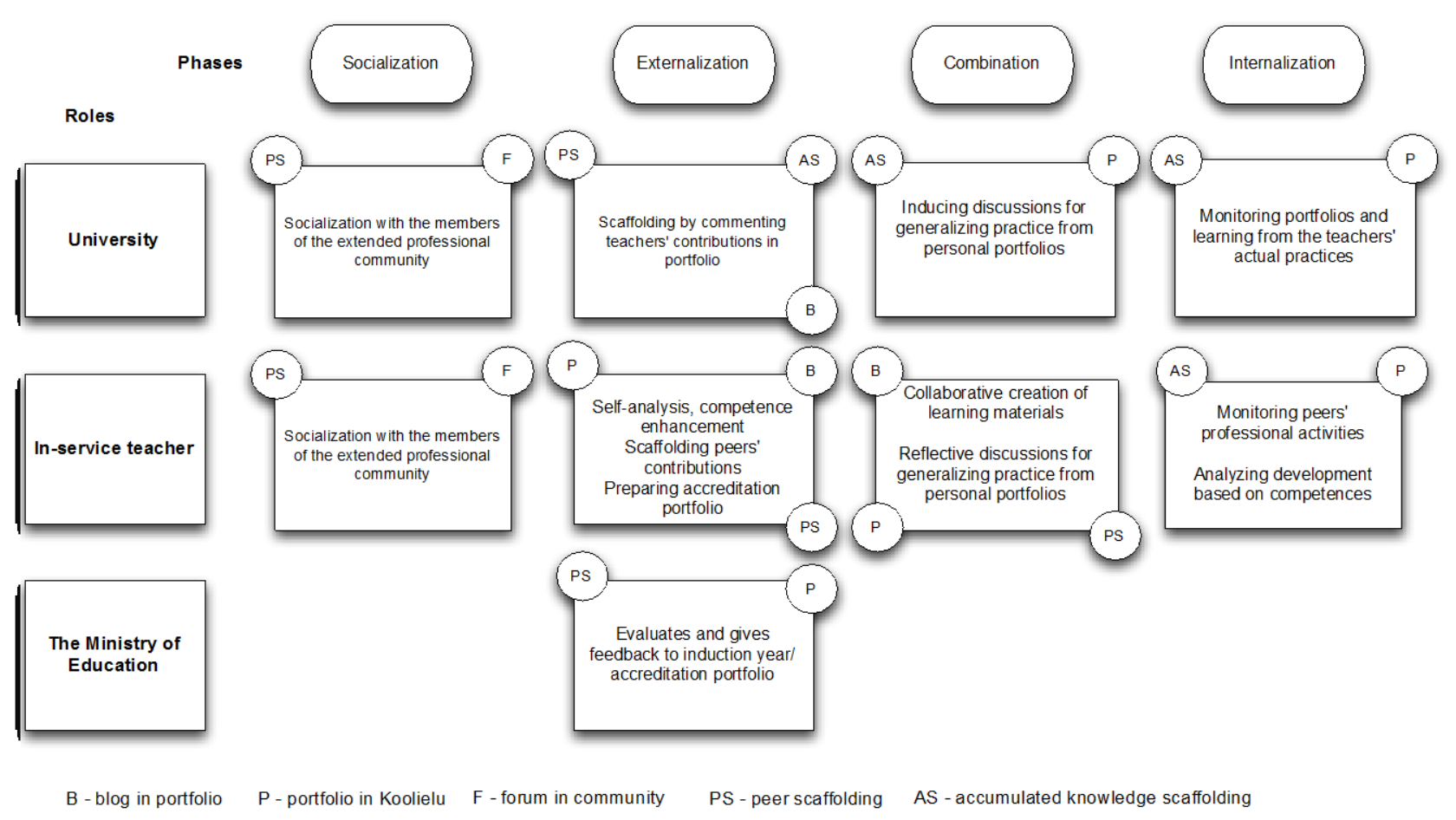

Figure 2. The technologically supported LKB practices in the extended professional community. 
In the evaluation phase the LKB practices of the framework were analysed to determine if they could be systematically implemented among the community members. Based on the data from the log-files, the following were identified.

LKB practices that were actually carried out in the accreditation course community:

- Socialization - members socialized in the forum with the aim of finding support for their individual learning needs (technical advice, privacy issues, etc.) or for personal reasons.

- Externalization - externalization of the professional knowledge in the weblog through reflection. Teachers wrote a self-analysis based on their educational technology competency and evaluated their development. Their comments included reflection and they provided feedback to their peers as part of the externalization.

- Combination - the community members combined their individual reflections about the competency enhancement process with the joint generalization of how to achieve certain educational competences. Also, domain experts initiated discussions in the forum regarding the organizational norms associated with the accreditation process, in order to promote the teachers' knowledge construction and reflection.

- Internalization - teachers' individually analysed their competences based on the competency model, accreditation requirements, reflections on peers' weblogs, and feedback from the community members. They learned from their colleagues and from the community knowledge.

To determine the interrelationships between the practices of the community members, a correlation analysis of activity sequences was conducted (see Table 1). In the table, T or $\mathrm{O}$ behind the practices indicates teacher $(\mathrm{T})$ or domain expert $(\mathrm{O})$ and the letter in the bracket indicates the SECI phase. 
Table 1

Correlation Analysis of LKB Practives

\begin{tabular}{|c|c|c|c|c|c|c|c|c|c|c|}
\hline & & $\begin{array}{l}\text { View } \\
-\mathrm{T}\end{array}$ & $\begin{array}{l}\text { View } \\
\text { _O }\end{array}$ & $\begin{array}{l}\text { E(Entr } \\
\text { y)T }\end{array}$ & $\begin{array}{l}\text { E(Comme } \\
\text { nt)T }\end{array}$ & $\begin{array}{l}\text { E(Comme } \\
\text { nt)O }\end{array}$ & S_T & $\mathrm{S} \_\mathrm{O}$ & $\begin{array}{l}\mathrm{C} \\
\mathrm{T}\end{array}$ & C \\
\hline View_T & $r$ & 1 & & & & & & & & \\
\hline View_O & $r$ & $\begin{array}{l}0.828 \\
* *\end{array}$ & 1 & & & & & & & \\
\hline $\mathrm{E}$ (Entry)T & $r$ & $\begin{array}{l}0.722 \\
* *\end{array}$ & $\begin{array}{l}0.626 \\
*\end{array}$ & 1 & & & & & & \\
\hline $\begin{array}{l}\text { E(Comme } \\
\text { nt)T }\end{array}$ & $r$ & $\begin{array}{l}0.651 \\
* *\end{array}$ & & & 1 & & & & & \\
\hline $\begin{array}{l}\text { E(Comme } \\
\text { nt)O }\end{array}$ & $\mathrm{r}$ & $\begin{array}{l}0.822 \\
* *\end{array}$ & $\begin{array}{l}0.898 \\
\text { ** }\end{array}$ & & $0.691^{* *}$ & 1 & & & & \\
\hline $\mathrm{S}_{-} \mathrm{T}$ & $\mathrm{r}$ & $\begin{array}{l}0.650 \\
* *\end{array}$ & $\begin{array}{l}0.607 \\
*\end{array}$ & $\begin{array}{l}0.874 * \\
*\end{array}$ & & & 1 & & & \\
\hline S_O & $r$ & $\begin{array}{l}0.641 \\
*\end{array}$ & $\begin{array}{l}0.791 \\
* *\end{array}$ & $\begin{array}{l}0.662 * \\
*\end{array}$ & & $0.567 *$ & $\begin{array}{l}0.750 \\
* *\end{array}$ & 1 & & \\
\hline $\mathrm{C}_{-} \mathrm{T}$ & $r$ & $\begin{array}{l}0.789 \\
* *\end{array}$ & $\begin{array}{l}0.888 \\
* *\end{array}$ & $0.571^{*}$ & & $0.752^{* *}$ & & & 1 & \\
\hline C_O & $\mathrm{r}$ & & & & & & $\begin{array}{l}0.520 \\
*\end{array}$ & $\begin{array}{l}0.52 \\
5^{*}\end{array}$ & & 1 \\
\hline
\end{tabular}

* Correlation is significant at the $\mathrm{p}<0.05$ level (2-tailed); ** Correlation is significant at the $\mathrm{p}<0.01$ level (2-tailed)

The dataset was organized according to weekly LKB frequencies and was enabled to search for the correlations between the community members' different LKB practices so that predictions could be made as to how the LKB framework was functioning as a system. Correlation analysis indicated that the teachers' viewings of the blog and forum were significantly interrelated with writing the blog entry $(r=0.722)$, commenting on the community members' blog (0.651), socialization activities by peers $(r=0.650)$, and combination activities by peers (0.789). This may indicate that a teacher looks at what other community members have performed in the system and then performs different LKB practices (belonging to S, E, C, in the LKB framework). It also means that the knowledge created by other community members and shared as a community resource serves as community knowledge promoting other types of LKB. Correlation occurred between the socialization and externalization activities of teachers. Those teachers who socialized in the forum were very likely to write a blog entry as well in the same week ( $\mathrm{r}$ 
$=0.874$ ). Writing a blog entry by the teachers was also interrelated with the teachers' collaborative group-based knowledge-building tasks ( $\mathrm{r}=0.571)$. These findings indicate, that in all the different LKB practices, the LKB framework suggested they had significant mutual correlations, allowing the community members to benefit from the mutual synergy between LKB practices in different SECI phases. The possible causal relationships among different LKB practices of the framework are discussed in the subsection below.

\section{Scaffolding LKB in the Extended Professional Community}

One of the research interests was to explain how different community members in the extended professional community - the teachers and the domain experts - could influence their peers' LKB. The correlation analyses (see Table 1) that do not allow detecting causal relations indicated that several teachers' and domain-experts' LKB practices in different SECI phases were correlated. For example, teachers' socialization activities were related to the domain experts' socialization $(r=0.750)$ and combination activities ( $r=0.520)$. It may presumed that if a teacher socialized in the forum with community members, the domain expert also performed social communications, or, alternatively, proposed some of the discussion threads to prompt teachers' collaborative knowledge building in the forum. Teachers' viewing of blogs and forum entries were correlated with the domain expert's commenting on the teachers' blogs $(r=0.822)$ and the domain experts' socialization activities $(r=0.641)$. The domain experts' viewing of blog and forum entries was correlated with the teachers' writing a blog entry ( $r=$ 0.626), indicating that domain experts monitored community members' contributions. Teachers' blog entries were interrelated with domain experts' comments ( $r=0.898)$. Teachers' blog entries were also interrelated with the domain experts' socialization in the forum ( $r=0.663)$. Also domain experts' "views" of blogs and forum posts were correlated with teachers' socialization ( $r=0.607$ ) or combination-related $(r=0.888)$ discussions in the forum and domain experts' socialization in the forum ( $r=0.791)$. Teachers' and domain experts' comments in the weblog were interrelated ( $r=0.691)$, suggesting that these scaffolding actions may be mutually induced.

An assumption can be made from the results of the correlation analysis that teachers monitored each other in different SECI phases, and this might have prompted their LKB practices. Also, it was found that the domain experts in the extended professional community were closely monitoring teachers' LKB practices and providing scaffolding as well as trying to prompt teachers' to participate in different LKB practices. A correlation appeared between scaffolding activities (comments) of teachers and domain experts. It was assumed that the domain experts' comments might have also encouraged teachers to support their peers.

In order to validate some of these assumptions that were made based on the correlation analysis results, and systematically interpret the interrelations between LKB practices and scaffolding in a professional community, the authors investigated the causal 
dependencies between the indicators using the B-course ${ }^{1}$ analysis toolkit and Bayesian modelling (see Figure 3). Such a naïve dependency model can be used to explain how different activities might be causally interrelated and be influencing the community members' LKB. However, the naïve model considers dependencies as if no other variables had influence on the system. Therefore, these results may lose some of their explanatory power, since in a social system there are always some aspects that are not measured.

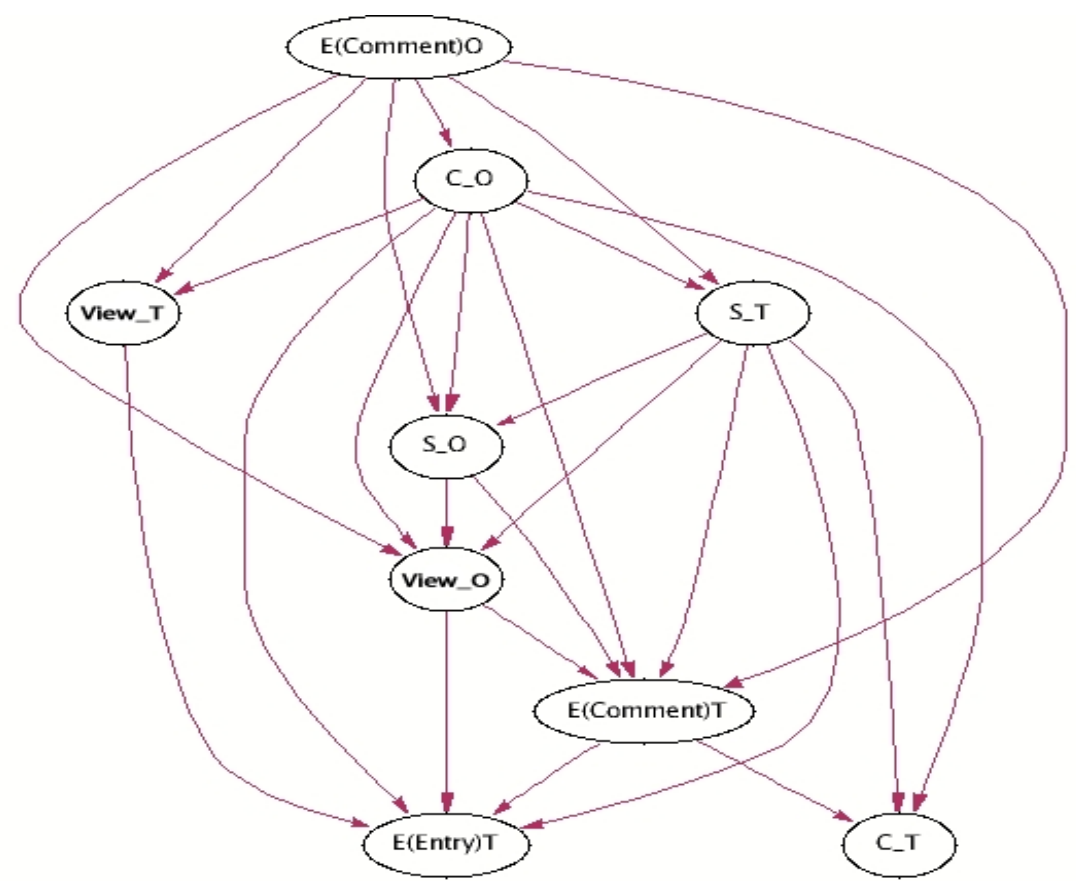

Figure 3. Naive Bayesian dependency model for LKB practices.

The dependency model (see Figure 3) revealed the following causal interrelations (the abbreviations used are explained in the Data Collection and Analysis section). The domain experts' comments had no direct influence on prompting teachers' entries in the blog. The domain experts' comments (E(Comment)O) on the teachers' weblog entries caused the teachers to comment $(\mathrm{E}(\mathrm{Comment}) \mathrm{T})$ on the weblogs. This may indicate that domain experts do not influence teachers' LKB practices directly, but they encourage community members to comment on their peers, and that the commentary influences them to write blog entries. The domain experts had more direct influence on the teachers' knowledge building in the combination phase. Teachers' combination activities (C_T) were dependent on domain experts' combination activities (C_O) in the forum. The teachers' blog entries were induced by several other teachers' LKB practices, for example, the teachers' socialization and combination activities in the forum.

$1 \quad$ http://b-course.cs.helsinki.fi 
Teachers' combination activities (C_T) were also dependent on teachers' socialization activities ( $\left.\mathrm{S}_{-} \mathrm{T}\right)$ and teachers' comments (E(Comment)_ $\mathrm{T}$ ) in the weblog. It can be assumed that teachers' socialization and comments in the weblog may prompt teachers to perform the knowledge building practices in the combination phase. However, there was no direct causal influence, neither between teachers' knowledge building in the combination phase and their reflections in the blog nor vice versa. Note that in the correlation analysis, a weak correlation was found between teachers' knowledge building in the combination phase and individual reflections in their blogs in the externalization phase.

The dependency model demonstrated how the LKB practices might be interrelated and supportive of each other and facilitate their validation in the LKB framework application in the professional community. The authors particularly found that the domain experts may have more direct influence on the combination activities in the forum, and they could indirectly influence teachers to comment on their peers' reflections in their blogs, which in turn might prompt individual reflections in the weblog. However, these results do not allow the assumption that domain experts and teachers would take similar roles in a naturally occurring professional community. There were some differences between the correlation analysis results and the dependency model; testing the probability of causal dependencies between different LKB practices, as part of the system in this specific naïve dependency model, did not support certain correlations that were found. In general, the results of the naïve dependency model may be considered as one of the more probable variants in how LKB practices might be dependent on each other.

\section{Discussion}

This section discusses how the socio-technical system can promote LKB (see Figure 3). Previously, Herrmann (2009) and Mandl and Fisher and Weinberger (2002) noted that the sharing of individual knowledge and collaborating on group knowledge as well as scaffolding to provide feedback for learning and promoting collaboration are all important in the socio-technical systems. The present study broadens the knowledge of how different learning and knowledge building practices and scaffolding might be interrelated in the extended professional e-portfolio communities. Using the example of a teachers' professional community, a description is provided to explain how a sociotechnical system works systemically and to illustrate the purpose of different types of LKB practices and scaffolding.

Data based on the analysis of the log-files demonstrated how teachers' contributions are influenced by the contributions of the other members in the system. It was found in particular that the domain experts may have more direct influence on knowledge building in the forum, and they could indirectly influence teachers to comment on their peers' reflections in blogs that in turn might prompt individual reflections in the weblog. These findings are similar to those in the study of Pata et al. (2006). They found that in 
the context of the student-tutor chatting in a synchronous environment, the influence that comes from peers who perform similar scaffolding acts as tutors might promote their peers' productive actions more than direct tutor-scaffolding. The peers' scaffolding in that study was promoted by the tutors' scaffolding activities, which is similar to the results found in the present study.

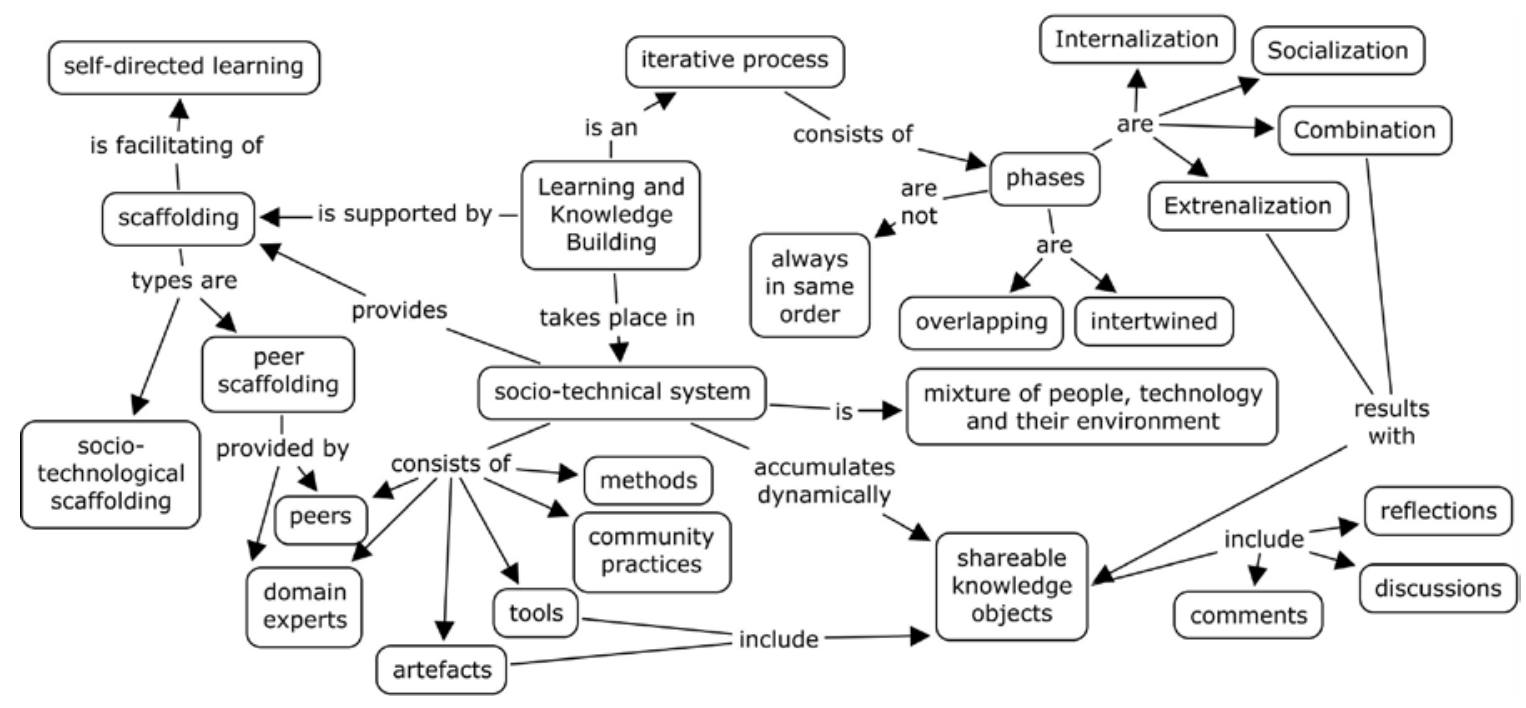

Figure 4. The LKB framework in the socio-technical system for teachers' professional development.

The synergy between different LKB practices has been described in the Results section. The results of the analysis of the log-files indicated that LKB practices for socialization, externalization, combination, and internalization are systemically intertwined and influence each other. Based on the collected data, the LKB framework highlights scaffolding elements that influence teachers' LKB. The current study distinguished two thoroughly intertwined scaffolding dimensions, social and technological, as was proposed by Pea (2004). Without community members the socio-technical system could not function (Lytras \& Pouloudi, 2006). Interactions of individuals in the system and their contributions to the community knowledge resources are important for the sociotechnical system. With their LKB practices, individuals create the dynamic flow of knowledge within the system between individual and organizational knowledge (Nonaka \& Takeuchi, 1995), enabling peer-scaffolding and socio-embedded scaffolds for other community members. Through the LKB practices in the socio-technical system, the knowledge of teachers is created, combined, shared, stored, and accumulated. Knowledge accumulation as a socio-embedded scaffold is supported by different functionalities like weblog, forum, and learning resources. Accumulated knowledge becomes available to community members for learning or for knowledge-building purposes. Individual knowledge is combined and evolves into community-level 
knowledge (Weber, Schoefegger, Ley, Lindstaedt, Bimrose, Brown, et al., 2009) and can be used, for example, in teacher training, when preparing in-service courses, redesigning curricula, or restructuring qualification systems. Community members' different types of LKB practices with community tools may provide different types of scaffolding. This study indicated that domain-experts' interactions directly influence teachers' knowledge building practices in the forum. However, the teachers' reflections in weblogs were more directly influenced by other teachers' comments in the blogs, rather than by the domain-experts' comments.

\section{Conclusion}

This study proposed how the technologically supported LKB practices in an extended professional community may be promoted by scaffolding. The study highlighted the importance of two types of scaffolding for facilitating LKB in the socio-technical system: (a) one performed by the peers and (b) one that appears as an accumulation of the community-generated knowledge and sharing it in the socio-technical system. Teachers' LKB should focus on the interactions between community members as scaffolds and emphasize the opportunities that technology provides, such as scaffolds for storing, reusing and sharing reflections, and organizing knowledge-building practices. These observations, which show how two types of scaffolding influence teachers' LKB, reiterate similar findings from previous studies of online communities (Pea, 2004; Lytras \& Pouloudi, 2006; Pata et al., 2006). It is nevertheless worth considering that the current study revealed peer-scaffolding across different types of peers in the extended professional community; teachers placed a greater value on it and were more influenced by the scaffolding that came from the other teachers, not from the domain experts. The current study indicated that in the case where teachers' workplace learning is informal but they are expected to analyse their professional development and share their experiences, the support from similar peers is more valuable. This study assumes that scaffolds for LKB in a socio-technical system are intertwined because without technology or with a lack of human resources, teachers' LKB may not be promoted.

The extended professional community in the socio-technical system was studied during an in-service course, which did not reflect the spontaneous and authentic setting of a professional community of teachers. According to the course goals, the domain experts purposefully encouraged LKB practices of teachers, initiating the knowledge-building discussions, preparing some LKB tasks, and commenting on their reflections in the blogs. Such a training-community setting might not directly replicate an extended community where all the members - the domain experts as well as teachers participate without external motivation. 


\section{Acknowledgements}

This study was funded by MER targeted research 0130159s08, and also by the IntelLEO project, which was funded by the FP7 ICT program of the European Commission (DG Information Society and Media, project no. 231590). This document does not necessarily represent the opinions of the European Community and the European Community is not responsible for any use that might be made of its content. 


\section{References}

Abrami, P. C., \& Barrett, H. C. (2005). Directions for research and development on electronic portfolios. Canadian J ournal of Learning and Technology, 31(3), 115.

Acosta,T., \& Liu, Y. (2006). ePortfolios: Beyond assessment. In A. J afari \& C. Kaufman (Eds.), Handbook of research on ePortfolios (pp. 15-23). Hershey, PA: Idea Group Publishing.

Boyle, B., While, D., \& Boyle, T. (2004). A longitudinal study of teacher change - What makes professional development effective? The Curriculum J ournal, 15(1), 4568.

Creswell, J . W. (2005). Educational research (2 $2^{\text {nd }}$ ed.). Upper Saddle River, NJ : Pearson Education.

Duncan-Howell, J. (2007). On-line communities of practice and their role in the professional development of teachers (PhD thesis). Queensland University of Technology.

Goodland, J. I. (1994). Educational renewal: Better teachers, better schools. San Francisco, CA: J ossey Bass.

Hargreaves, A. (1993). Individualism and individuality: Reinterpreting the teacher culture. In J. W. Little \& M. W. McLaughlin (Eds.), Teachers' work: Individuals, colleagues and context (pp. 51-75). New York: Teaches College Press.

Harri-Augstein, E., \& Thomas, L. (1991). Learning conversations: The self-organized learning way to personal and organizational growth. London: Routledge \& Kegan Paul.

Hauge, T. E. (2006). Portfolios and ICT as means of professional learning in teacher education. Studies in Educational Evaluation, 32, 23-26.

Herrmann, T. (2009). Socio-technical appropriation of Web2.0 for continuing learning on the job. In 'CSCW 2009 - Workshop: "What to expect from Enterprise 3.0".

Huberman, M. (2001). Networks that alter teaching: Conceptualisations, exchanges and experiments. In J . Soler, A. Craft \& H. Burgess (Eds.), Teacher development Exploring our own practice (pp. 141-159). London: Paul Chapman Publishing Ltd.

Hunter, B. (2002). Learning in the virtual community depends upon changes in local communities. In K. A. Renninger \& W. Shumar (Eds.), Building virtual communities (pp. 96-126). Cambridge: Cambridge University Press. 
Lom, E., \& Sullenger, K. (2010). Informal spaces in collaborations: Exploring the edges/boundaries of professional development. Professional Development in Education, 37(1), 55-74.

Lytras, M. D., \& Pouloudi, A. (2006). Towards the development of a novel taxonomy of knowledge management systems from a learning perspective - an integrated approach to learning and knowledge infrastructures. Journal of Knowledge Management 10(6), 64-80.

Mackey, J., \& Evans, T. (2011). Interconnecting networks of practice for professional learning. International Review of Research in Open and Distance Learning, 12(3), 1-18.

Marrero, M. E., Woodruff, K. A., Schuster, G. S., \& Riccio, J. F. (2010). Live, online short-courses: A case study of innovative teacher professional development. International Review of Research in Open and Distance Learning, 11(1), 81-95.

Mushayikwa, E., \& Lubben, F. (2009). Self-directed professional development - hope for teachers working in deprived environments? Teaching and Teacher Education, 25(3), 375- 382.

Myllymäki, P., Silander, T., Tirri, H., \& Uronen, P. (2002). B-Course: A web-based tool for Bayesian and causal data analysis. International Journal on Artificial Intelligence Tools, 11(3), 369-387.

Nonaka, I., \& Takeuchi, H. (1995). The knowledge-creating company: How J apanese companies create the dynamics of innovation. Oxford: Oxford University Press.

Pata, K., \& Laanpere, M. (2008). Supporting cross-institutional knowledge building with Web 2.0 enhanced digital portfolios. In The 8th IEEE International Conference on Advanced Learning Technologies (ICALT 2008), Santander, Cantabria, Spain, ed. P. Diaz, I. Aedo, and E. Mora, 798-800. Washington: IEEE Computer Society Press.

Pata, K., Lehtinen, E., \& Sarapuu, T. (2006). Inter-relations of tutors' and peers' scaffolding and decision-making discourse acts. Instructional Science, 34(4), 313- 341.

Pea, R. D. (2004). The social and technological dimensions of scaffolding and related theoretical concepts for learning, education, and human activity. J ournal of the Learning Sciences, 13, 423- 451.

Puntambekar S., \& Hubscher R. (2005). Tools for scaffolding students in a complex learning environment: what have we gained and what have we missed? Educational Psychologist, 40, 1- 12. 
Scardamalia, M., \& Bereiter, C. (2003). Knowledge building. In Encyclopedia of education ( $2^{\text {nd }}$ ed., pp. 1370-1373). New York: Macmillan Reference, USA.

Scardamalia, M., \& Bereiter, C. (1994). Computer support for knowledge-building communities. The J ournal of the Learning Sciences, 3(3), 265-283.

Scardamalia, M., Bereiter, C., \& Lamon, M. (1994). The CSILE project: Trying to bring the classroom into World 3. In K. McGilley (Ed.), Classroom lessons: Integrating cognitive theory and classroom practice (pp. 201-228). Cambridge, MA: MIT Press.

Stoll, L., \& Louis, K. S. (2007). Professional learning communities: Elaborating new approaches. In L. Stoll \& K. S. Louis (Eds.), Professional learning communities: Divergence, depth, and dilemmas. Berkshire: Open University Press.

Tammets, K., \& Pata, K. (2012). Implementation model for cross-organizational learning and knowledge building: A case of teachers' accreditation. Systems Research and Behavioral Science.

Tammets, K., Pata, K., \& Laanpere, M. (2012). Implementing a technology-supported model for cross-organisational learning and knowledge building for teachers. European J ournal of Teacher Education, 35, 57- 75.

Tammets, K., Pata, K., \& Laanpere, M. (2011). A scenario for portfolio-based accreditation of teachers' competences. In Estonian context Proceedings of the 3rd international Conference on Computer Supported Education (CSEDU) (pp. 280- 289). SciTePress Digital Library.

Van Eekelen, I. M., Vermunt, J .D., \& Boshuizen, H.P.A. (2006). Exploring teachers' will to learn. Teaching and Teacher Education, 22, 408-423.

Weber, N., Schoefegger, K., Ley, T., Lindstaedt, S., Bimrose, J ., Brown, A., \& Barnes, S. (2009). Knowledge maturing in the semantic mediaWiki: A design study in career guidance. In U. Cress, V. Dimitrova \& M. Specht (Eds.), Learning in the Synergy of Multiple Disciplines: Proceedings of the 4th European Conference on Technology Enhanced Learning, Vol. 5794 (pp. 700-705). Heidelberg: Springer.

Weinberger, A., Fischer, F., \& Mandl, H. (2002). Fostering computer supported collaborative learning with cooperative scripts and scaffolds. In the Proceedings of the Computer Supported Collaborative Learning (CSCL 2002) (pp. 573 $574)$.

Wenger, E. (1998). Communities of practice: Learning, meaning and identity. Cambridge: Cambridge University Press. 
Wood, D. J., Bruner, J. S., \& Ross, G. (1976). The role of tutoring in problem solving. J ournal of Child Psychiatry and Psychology, 17(2), 89-100.

Yin, R. K. (1984). Case study research: Design and methods. Newbury Park, CA: Sage.

\section{Athabasca University $\mathbf{A}$}

(9) ()

